\title{
El culto tradicional y la realidad social La arquitectura religiosa de Richard J. Neutra
}

\author{
The traditional worship and social reality. Richard J. Neutra's religious architecture
}

Brett Tippey

https://doi.org/10.17979/aarc.2011.2.2.5056

En el mundo moderno occidental, el culto tradicional cristiano y la realidad social parecen cada vez más inconexos. El culto tradicional cristiano queda en la antigüedad, aislado de la vida actual y moderna; y la realidad social vuelve la espalda a la riqueza cristiana desarrollada a través de los siglos, buscando una nueva espiritualidad mezclada, desarraigada y superficial. Esta separación entre lo espiritual y lo cotidiano niega el poder de ambos y deja una profunda carencia en el alma del ser humano moderno.

Como uno de los arquitectos modernos más importantes, Richard Neutra reconoció el cometido particular de la arquitectura en la difícil reconciliación de estos dos elementos supuestamente incompatibles. Para él, todas las empresas de la experiencia humana se conectan íntimamente, ya sean la ciencia, el arte y la espiritualidad, o el individuo, la comunidad y la deidad. Por lo tanto, la arquitectura, como diseño de los lugares que el ser humano habita, representa el nexo entre todas las cosas, porque según él, «el ámbito es la conexión».

Aunque poco conocidas, las obras religiosas de Neutra, representan una arquitectura simultáneamente actual y espiritual. No se basan en una tradición institucional, histórica y agotada, sino que aceptan la tradición como un organismo vivo, que se adapta continuamente a la vida moderna. Interpretando las palabras de Neutra, la revista madrileña Informes de la Construcción declaró que «la religión debe ser viva, evolutiva, y en que los feligreses, ni son primitivos cristianos, a los que se habla en sombrías catacumbas, ni pintorescos cruzados del siglo XI», y propone la obra de Neutra como «una feliz realización, adecuada para la angustiada y esperanzada gente de hoy»².

El tema constante en la arquitectura de Neutra, tanto religiosa como secular, es su entendimiento profundo y particular del ser humano en toda su complejidad. Enfrentándose a la tendencia moderna hacia un humanismo que niega la relevancia de Dios y lo divino en la experiencia humana, Neutra insistía que el ateísmo es una «rebelión infantil y áspera contra algo que el hombre nunca ha podido - y casi nunca ha querido - evi$\operatorname{tar} »^{3}$. Neutra continuó este discurso teísta, proclamando que «el arquitecto del futuro se ocupará-modesto y lleno de adoración - en alojar conjuntamente el cuerpo y el alma humana, y servirá con toda fidelidad sus actividades y sus reflejos. Venerará la creación con más vigor que sus antepasados, y rendirá debido culto a la divinidad y a las misteriosas fuerzas que alientan detrás de la vida aparente» ${ }^{4}$.

Informes de la Construcción subrayó la riqueza de la unión entre lo físico y lo espiritual en toda la obra de Neutra. En concreto, la revista describió la iglesia Garden Grove (1962) así: «Richard Neutra ha diseñado a escala humana, pensando en el hombre, la mujer y el niño, relacionados con el culto» ${ }^{5}$. Así, las dimensiones biológicas, físicas y espirituales del ser humano quedan 

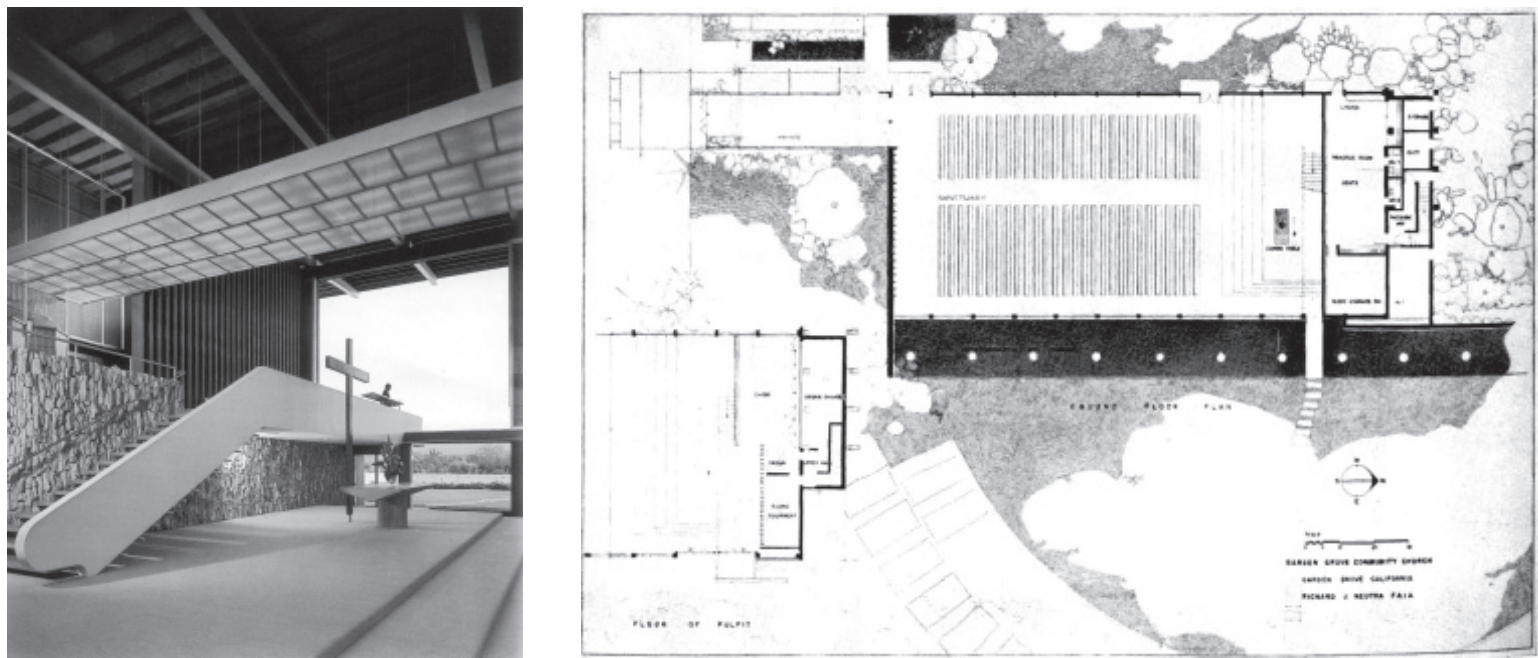

Figs. 1-3. Iglesia Garden Grove, 1961. Vista interior de la nave con el altar en primer plano, primera planta y vista general exterior de la entrada principal.

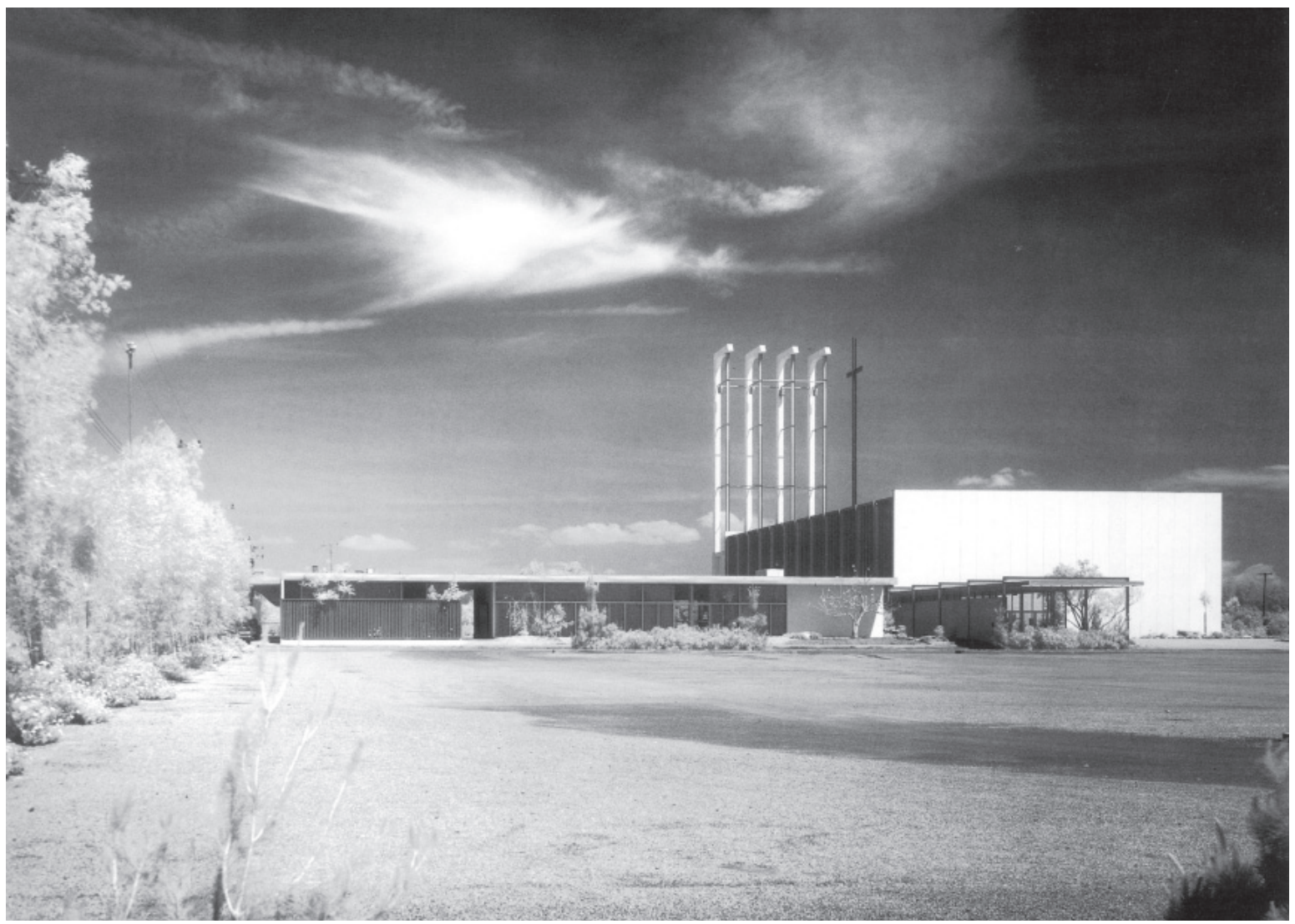



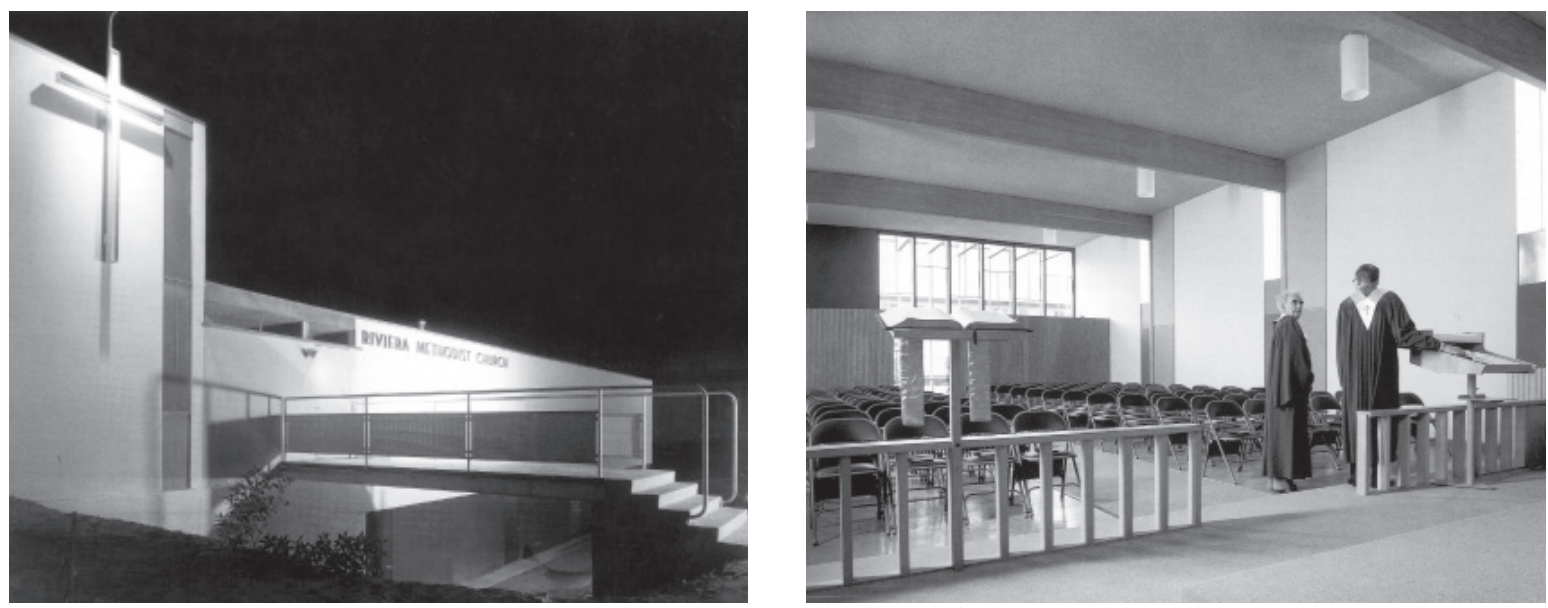

Figs. 4-5. Iglesia Riviera, 1958. Vista exterior de la entrada principal y vista interior de la nave con Neutra en segundo plano.

unidas en la arquitectura, debido a esta reintroducción de lo divino en lo cotidiano.

Robert Schuller, párroco que colaboró con Neutra en el proyecto de la iglesia Garden Grove, encontró en Neutra ese arquitecto del futuro, proclamando que «no creo que te des cuenta de que una razón por la cual has tenido tanto éxito incomparable como arquitecto ha sido que no solo tienes dones intuitivos de expresión artística y sensibilidad humana - sino que tienes otro don... Es el espíritu-Dios dentro de ti» 6 .

Al encontrar en Neutra un alto nivel de espiritualidad, Schuller recibió el diseño para la Garden Grove con gran entusiasmo. En una carta personal al arquitecto con fecha posterior a la construcción de la iglesia, el párroco comparó la obra terminada a una rosa en flor ${ }^{7}$. Además, en 1968 Schuller se refirió a la iglesia como un ejemplo de la arquitectura más refinada que se realizará en el siglo XX, y empleó las palabras del salmista para destacar la fuerza y la belleza de esta obra de Neutra: «Poder y hermosura en su santuario» ${ }^{8}$.

Neutra aceptaba lo físico del hombre como ser biológico, pero también insistía en su espiritualidad como ser creado a imagen de Dios; para él, estos dos aspectos eran indivisibles. Por lo tanto, toda arquitectura, sea religiosa o secular, debería alojar y alimentar tanto al espíritu como al cuerpo. Para Neutra, ningún edificio es meramente secular, ni solamente espiritual, sino que tiene que ocuparse de ambos aspectos ${ }^{9}$. Esta perplejidad no representa para Neutra ninguna contradicción, sino «un profundo conocimiento de la realidad» 10 .

Al proyectar la Garden Grove, Neutra se ocupó de la unión de estos dos aspectos claves del ser humano. «El objetivo del arquitecto fue encontrar una solución, con permanencia física y espiritual, por encima de las exigencias actuales; una casa de oración, en la que pudiera alcanzar un estado de contemplación tranquilo» ${ }^{11}$. Este intento de cumplir con las necesidades funcionales del programa y aún superarlas, mientras facilita el crecimiento del espíritu, llevó a Neutra a crear una arquitectura que responde adecuadamente a la condición humana en toda su plenitud.

Muchas veces la arquitectura religiosa se concibe como unión entre el hombre individual y la divinidad. Sin embargo, Neutra revisó esa posición bastante limitada, sumando a la espiritualidad individual una dimensión de comunidad, porque para él la espiritualidad humana es simultáneamente individual y colectiva. «La persona verdaderamente religiosa nunca llega a sentirse en absoluta soledad. Al margen de su consciencia, esa persona siente una multitud de creyentes iguales a sí mismo en la periferia de su visión. Cuando alza la vista esa persona siente más que ve de verdad. Siente profundamente la participación enorme de otros seres humanos en su esperanza y emociones» ${ }^{12}$.

Aún más, Neutra defendió que cualquier cultura o época histórica revela al hombre como un ser 


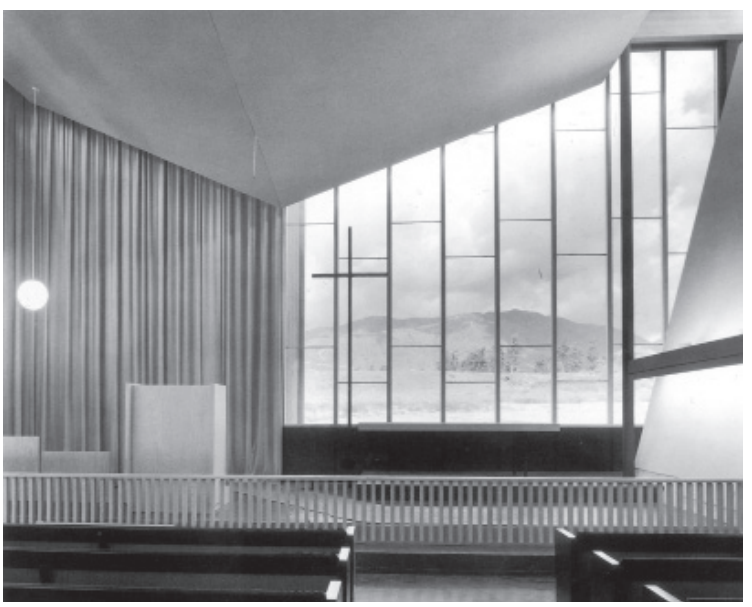

Figs 6-7. Iglesia Claremont, 1958. Vistas interiores de la nave.

comunitario ${ }^{13}$. En cuanto al cometido de la arquitectura en el acto espiritual comunitario, Willy Boesiger, al comentar sobre la iglesia Riviera de Neutra, sugirió que es demasiado reduccionista llamar iglesia un edificio que, por su fuerza arquitectónica, reúne y permite una unión y hermandad entre feligreses individuales en el acto de adoración ${ }^{14}$.

Si cualquier intento de separar lo físico de lo divino en el ser humano resulta inútil, según Neutra es igual de falso seguir ciegamente las tradiciones de la arquitectura religiosa, sin interrogarlas y reformarlas para llegar a una forma adecuada a la situación actual, porque muchas tradiciones representan solo una parte limitada en la amplia experiencia cristiana.

No hay por qué ver los orígenes del cristianismo en catacumbas, o pedir, hoy en día, una iglesia con tales memorias fracturadas. De hecho, todas las religiones, incluso el cristianismo, parecen haber comenzado al aire libre, muy cerca a la orilla del Jordán o cualquier otro río, rodeado por los verdes clorofílicos de la creación milagrosa ${ }^{15}$.

Para evitar esas memorias fracturadas, Neutra intenta rescatar las raíces de la iglesia primitiva que muchas veces se reunía al aire libre, sin ningún tipo de edificación permanente. Así fue el caso del pueblo de Israel que, durante el éxodo, realizó el culto en tiendas de campamento; también fue el caso de la iglesia de Filipos, donde San Pablo encontró un grupo de fieles

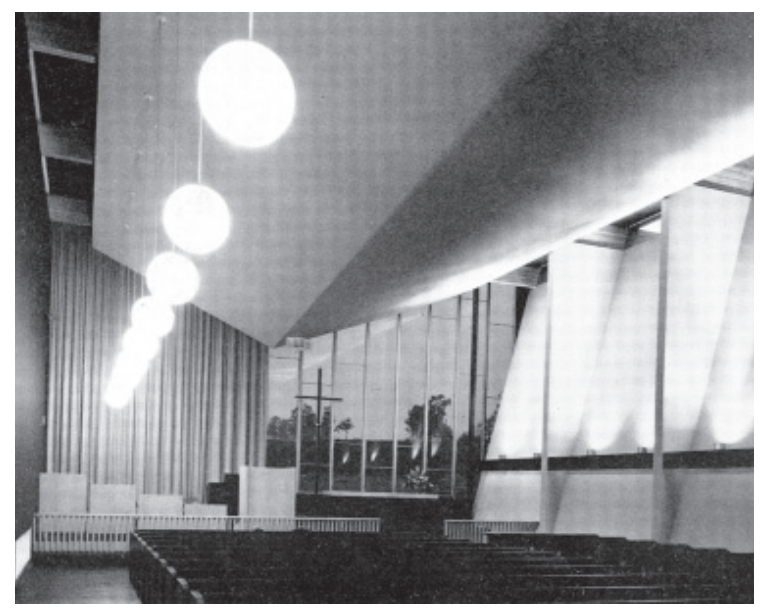

«fuera de la puerta, junto al río, dónde solía hacerse la oración» ${ }^{16}$. Obviamente, como arquitecto moderno Neutra no quiso decir que la arquitectura como edificación permanente sea un capricho innecesario. Al contrario, propone que la arquitectura religiosa, como toda arquitectura, debería de vincularse fluidamente con la Naturaleza.

Según Neutra, para llegar a tal tipo de vinculación la arquitectura, sea religiosa o secular, debería fundirse con el paisaje ${ }^{17}$. Esta atención a la Naturaleza se manifiesta a lo largo de su obra y sus escritos. Neutra suele referirse a la Naturaleza con mayúscula, otorgándole una entidad viva y propia que se identifica como aspecto de la divinidad de Dios ${ }^{18}$. Como parte fundamental de ser creado a imagen de Dios, el hombre guarda un profundo amor a la Naturaleza, siempre anhelando volver al aire libre ${ }^{19}$.

Por consiguiente, cuando Neutra proyectaba la arquitectura religiosa siempre la vinculó con la Naturaleza. Por ejemplo, Neutra explicó que el vestíbulo de la capilla Miramar (1957) se abre hacia el exterior, a través de una pantalla acristalada que invita a entrar ${ }^{20}$. De la iglesia Riviera (1958), Neutra dijo que «se encuentra...en un emplazamiento que domina un bello panorama; en la naturaleza, nada como el mar muestra a los ojos humanos la majestad de la creación. Por ello, esta iglesia, construida frente al mar, se ha proyectado teniendo muy en cuenta este emplazamiento 
BRETT TIPPEY

Figs. 8-10. Capilla Miramar, 1957. Primera planta, vista exterior del vestíbulo y vista del interior de la nave
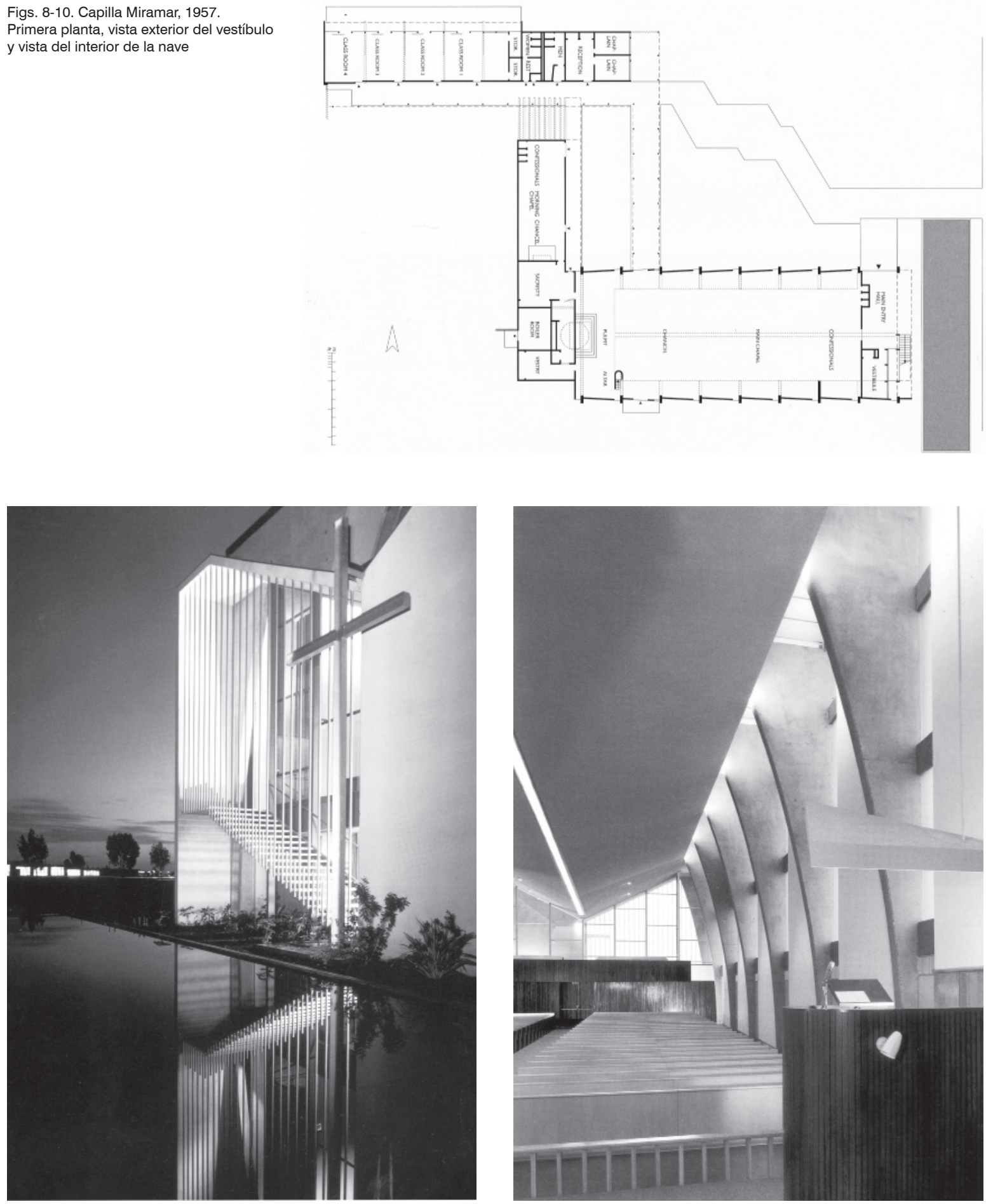

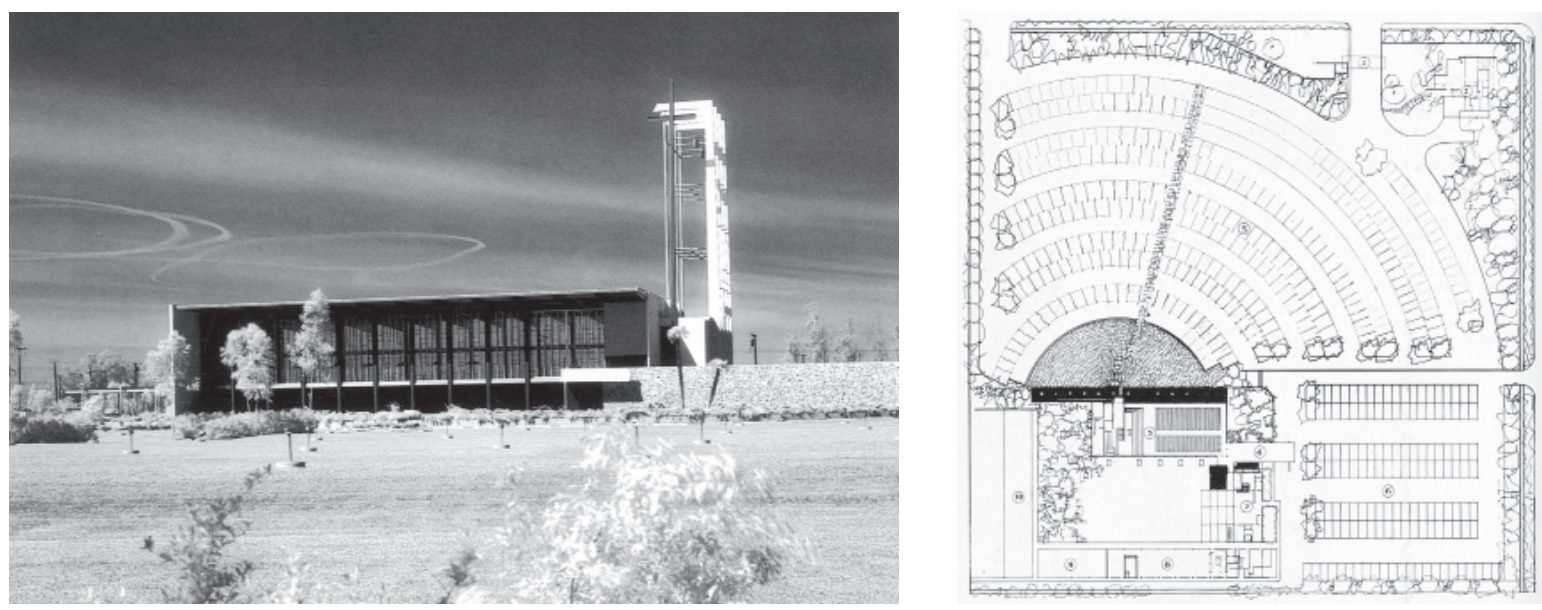

Figs. 11-12. Iglesia Garden Grove. Vista exterior y emplazamiento.

excepcional. Con las nubes y el cielo sobre el agua, en un cambio constante de iluminación, el interior de la iglesia se abre como una flor al espectáculo perpetuo del Océano Pacífico» ${ }^{21}$.

Aunque nunca fue construido, al describir el proyecto para una iglesia en Orlando (Florida), Neutra destacó la unión de la arquitectura con su entorno así: «La intimidad de los interiores y su relación con el mundo exterior deberían de ser absorbidas en este diseño integrador» ${ }^{22}$. Quizá el tratamiento más rico del vínculo de la arquitectura con la naturaleza en la obra religiosa de Neutra se encuentra en la iglesia Claremont (1958), cuyo gran ventanal detrás del altar introduce una vista del monte San Antonio que se abre en cuanto el feligrés se acerca al altar ${ }^{23}$.

La iglesia Garden Grove representa la culminación de la integración del espacio interior con el exterior, la relación entre el individuo con la comunidad y la unión de los aspectos físicos con los espirituales del ser humano. En la Garden Grove la nave tradicional con hileras de bancos dirigidos hacia el altar se extiende a una nave exterior a través de un muro acristalado corredero. Esta supuesta nave exterior da lugar a la realidad social californiana de los 60 , lugar y época dominados por el coche particular. En ella, los bancos se sustituyen por automóviles, también en hilera y dirigidos hacia el altar, pero bajo la bóveda del cielo y con amplificación acústica a través de altavoces en cada coche; así esta iglesia acomoda las particularidades de la cultura, y eso en una nave que se podría llamar «auto-iglesia» ${ }^{24}$. También concebida como un lugar de encuentro entre individuo y comunidad, la Garden Grove intenta extender al mundo moderno una mano abierta en vez de un dogma rígido de reglas de conducta 25 . En total, según Neutra, «el reverendo Schuller trajo una escala completamente nueva y una sensibilidad fresca a nuestro concepto tradicional de fe y rebaño. Vi la iglesia Garden Grove como una expresión de nuestra cultura mundial contemporánea, y de una religión mundial en evolución perpetua» ${ }^{26}$.

Así, en esta iglesia se entiende la forma en que Neutra intentó reunir el culto tradicional con la realidad social.

Quizá las teorías de Neutra sobre la arquitectura religiosa de hace medio siglo sirven de ejemplo para el siglo XXI, momento que se caracteriza también por la misma brecha entre el culto tradicional y la realidad social. Puede que las formas concretas en que Neutra intentó reconciliar la tradición con la actualidad sean problemáticas o incluso heréticas en nuestros tiempos. Sin embargo, el énfasis humanístico que domina la obra de Neutra, aplicado a la situación de hoy, podría producir una arquitectura que responde adecuadamente a las necesidades inherentes al ser humano moderno, aun manteniéndose fiel al mismo tiempo a la verdadera y amplia tradición cristiana. 


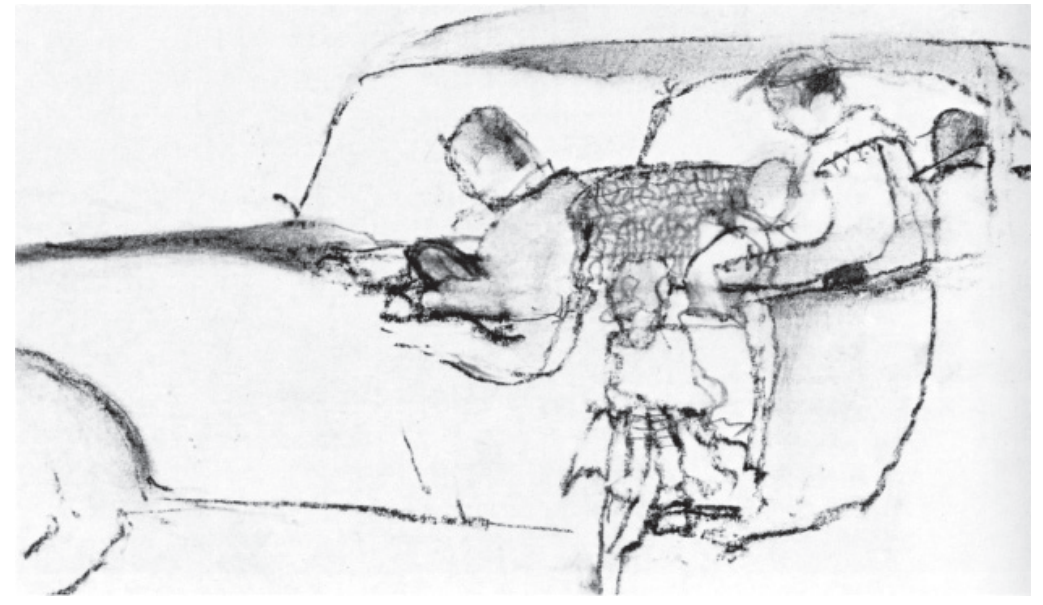

Fig. 13. Croquis de Neutra para el proyecto de la iglesia Garden Grove, mostrando una familia orando dentro del coche.

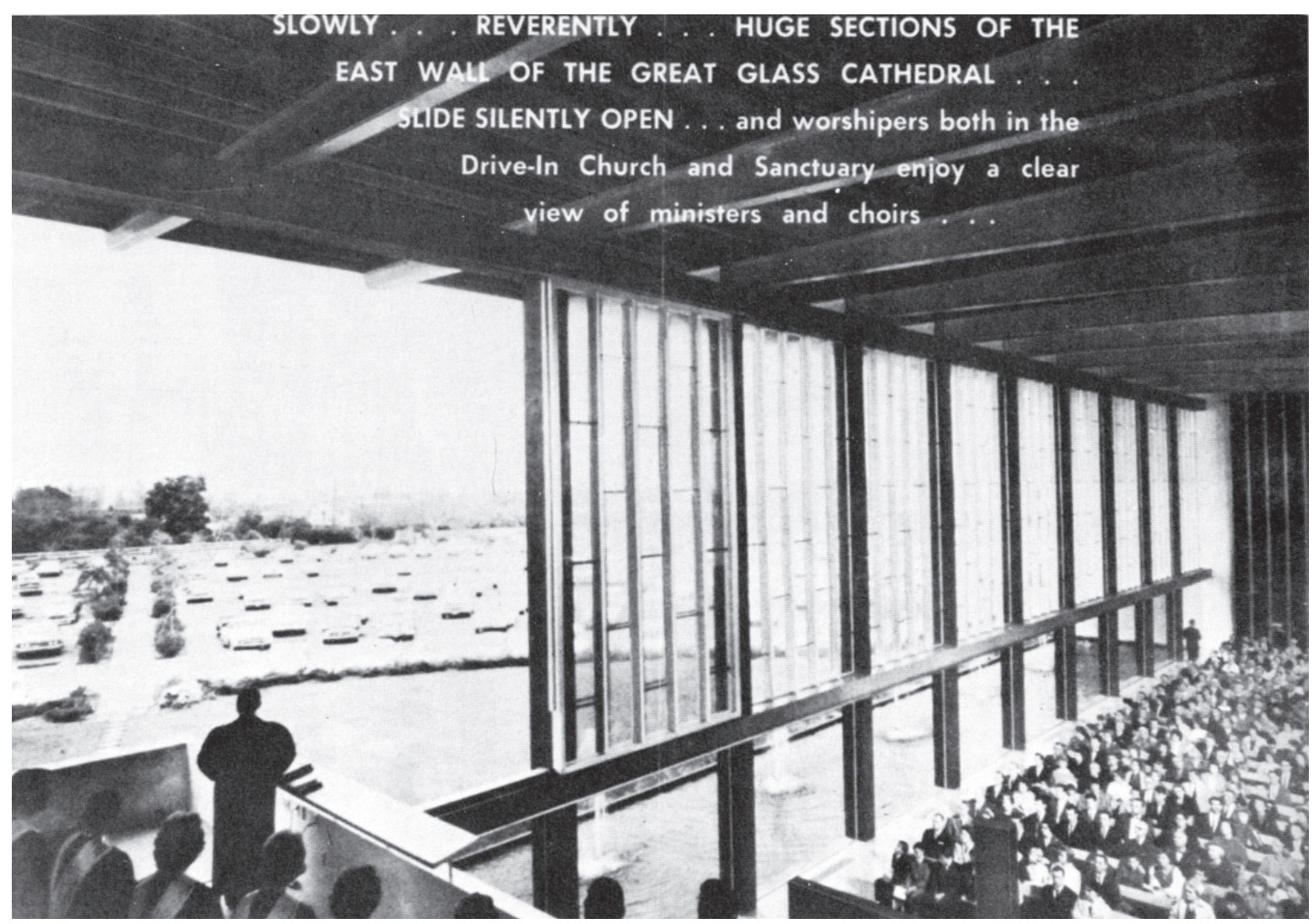

Fig. 14. Iglesia Garden Grove. Vista de las dos naves unidas a través de los ventanales abiertos.

El texto lee «Lentamente... reverentemente... secciones enormes del muro oriental de la gran catedral de cristal deslizan y abren silenciosamente... y los adoradores, tanto los en la 'auto-iglesia' como los dentro del santuario gozan de una vista clara de los pastores y el coro». 
Fig. 15. Iglesia Garden Grove. Vista desde dentro de la nave hacia la nave exterior con Neutra frente el púlpito.

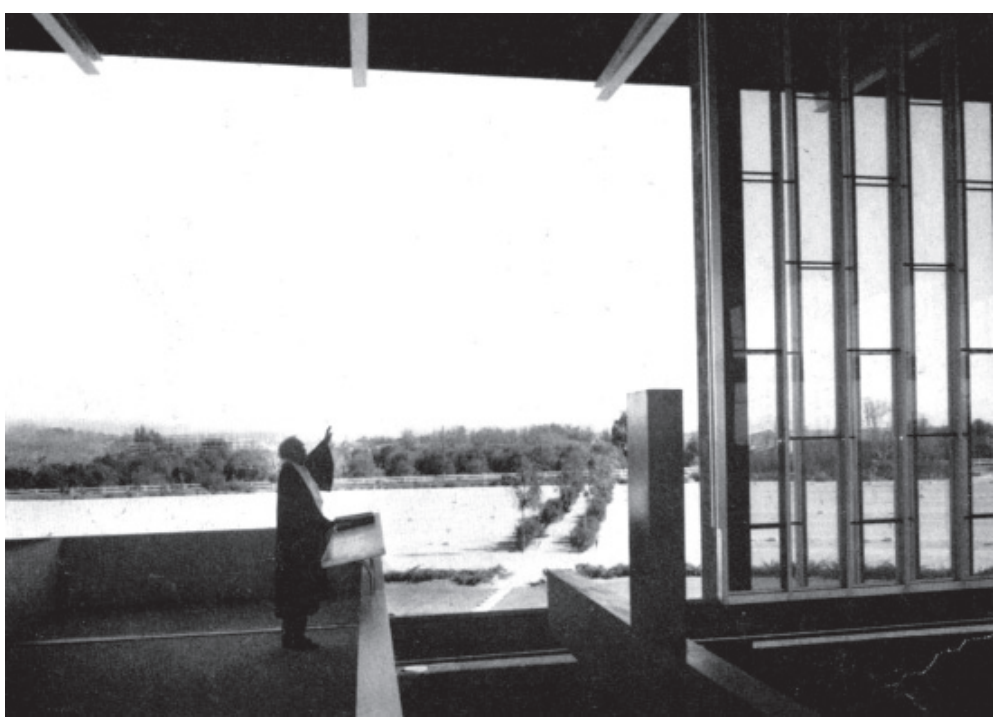

\section{NOTAS}

(1) Richard Neutra y William Marlin (ed.), «Nature Near: late essays of Richard Neutra», Capra Press, Santa Barbara, 1989; pág. 3.

(2) VVAA, «Iglesia en Garden Grove, California», Informes de la Construcción 159 (1964), 148-84.

(3) Richard Neutra, «¿Qué aspecto debe tener una iglesia?», Informes de la Construcción 118 (1960), 100-27.

(4 Loc. cit. Aunque nacido de una familia judía, Neutra no era practicante. Sin embargo, queda claro que respetaba las tradiciones religiosas en general y se interesaba en el desafío de la arquitectura religiosa moderna. Véase Thomas S. Hines, «Richard Neutra and the search for modern architecture: a biography and a history», Oxford University Press, New York, 1982); pág. 239.

(5) VVAA, «Iglesia en Garden Grove...», cit.

(6) Carta personal de Robert Schuller a Richard Neutra (26 de julio de 1967), en «Richard and Dion Neutra Papers», UCLA (Collection Number 1179 , caja 228 carpeta 4$)$.

(7) Loc. cit.; pág. 1-2

(8) Loc. cit. La cita bíblica es del Salmo 96, 6 .

(9) Cf. Richard Neutra, «Sounding Sensory Scales in Court and Church», en Idem. y William Marlin (ed.), «Nature Near...», cit.; pág. 73-74).

(10) Richard Neutra, «QQué aspecto...?», cit. Para permitir esta pluralidad en una sola arquitectura, Neutra la compara con el concepto del Elohim, que, aparte de su connotación de un Dios plural, es fundamental para el monoteísmo, tanto judaico como cristiano.

(11) VVAA, «Iglesia en Garden Grove...», cit.
(12) Richard Neutra, «Designing an Indoor-Outdoor Church» (17 de noviembre de 1969), en «Richard and Dion Neutra Papers», UCLA (Collection Number 1179, caja 177 carpeta 11); pág. 2.

(13) Idem, «World and Dwelling», Universe Books, Nueva York, 1962; pág. 19.

(14) Willy Boesiger (ed.), «Richard Neutra 1961-1966: Buildings and Projects» (vol. III), Girsberger, Zurich, 1966; pág. 178.

(15) Richard Neutra, «Designing an...», cit.; pág. 1.

(16) Hechos de los Apóstoles 16, 13.

(17) Richard Neutra, «¿Qué aspecto...?», cit.

(18) Barbara Mac Lamprecht, «Richard Neutra: Complete Works», Taschen, Köln, 2000; pág. 353. Muchas veces la mayúscula que aparece en la versión original (en inglés) de los textos de Neutra se pierde al ser traducidos al español.

(19) Richard Neutra, «Life and Human Habitat», Alexander Koch, Stuttgart, 1956; pág. 287.

(20) Idem, «¿Qué aspecto...?», cit.

(21) Loc. cit.

(22) Idem, «About the Orlando Church» (11 de noviembre de 1969), en «Richard and Dion Neutra Papers», UCLA (Collection Number 1179, caja 177 carpeta 11).

(23) Willy Boesiger (ed.), «Richard Neutra 1961-1966...», cit.; pág. 182.

(24) El término auto-iglesia (Drive-in Church) apareció en un panfleto de la iglesia. Véase fig. 15. Thomas S. Hines, «Richard Neutra and the search...», cit.; pág. 286.

(25) Richard Neutra, «Sounding Sensory Scales...», cit.; pág. 77.

(26) Ibidem; pág. 76. 